\title{
Assessment of effectiveness of synthetic diacylglycerols as emulsifiers in dispersion systems containing interesterified Turkey fat
}

\author{
Małgorzata Kowalska ${ }^{1} \cdot$ Magdalena Woźniak $^{2,3} \cdot$ Serge Tavernier $^{3} \cdot$ Anna Żbikowska $^{4} \cdot$ Łukasz Pazdur $^{3}$
}

Received: 3 February 2018 / Revised: 26 March 2018 / Accepted: 13 April 2018 / Published online: 21 April 2018

(c) The Author(s) 2018

\begin{abstract}
The purpose of this study was to form new dispersion systems based on chemically interesterified waste turkey fat containing sesame oil (2:3 wt./wt.) and to evaluate effectiveness of synthetized diacylglycerols stabilizing these emulsions. Sesame oil was used to enrich and improve turkey fat's composition with unsaturated fatty acids derived from oil. Physical properties of raw fats and fat blends (before and after the reaction) were determined. Increase of acid value and crystallization point was noted after the reaction, and no changes occurred in the fatty acid composition of the sesame oil and turkey fat blends. Diacylglycerols were synthesized from specified monoacylglycerols, then purified, and analyzed by means of Gel Permeation Chromatography (GPC) and Thin-Layer Chromatography (TLC). The role of the amount of synthetically obtained diacylglycerols (DAG) as emulsifiers in obtaining the stable emulsion product was examined. 6\% (wt./wt.) was found to be the smallest amount of DAG emulsifier needed to properly stabilize the prepared emulsions. The proposed new emulsion products could be applied as new food product formulations like mayonnaise sauces or dressings. Such formulations containing beneficial fats like turkey fat or sesame oil, as well as new structured diacylglycerols could meet customer requirements.
\end{abstract}

Keywords Synthesis · Diacylglycerols $\cdot$ Interesterification $\cdot$ Turkey fat $\cdot$ Emulsions

\section{Introduction}

Oils and fats contain triglycerides which typically consist of glycerol and saturated and unsaturated fatty acid esters [1]. Physical properties of commercial fats are closely associated the kinds of fatty acids and triacylglycerol compositions [2]. The type of fatty acid in each position profoundly affects physical behavior of fat and oil, while the relative proportions of every triacylglycerol in fat and oil are crucial to their

Małgorzata Kowalska

m.kowalska@uthrad.pl

1 Faculty of Material Science, Technology and Design, Kazimierz Pulaski University of Technology and Humanities, 27 Chrobrego St, 26-600 Radom, Poland

2 Faculty of Economics and Legal Sciences, Kazimierz Pulaski University of Technology and Humanities, 33 Chrobrego St, 26-600 Radom, Poland

3 Faculty of Applied Engineering, University of Antwerp, Salesianenlaan 90, 2660 Hoboken, Belgium

4 Faculty of Food Sciences, Warsaw University of Life Sciences (SGGW), Nowoursynowska St. 159C, 02-787 Warsaw, Poland overall behavior and stability. Composition of fats and oils has a great impact on texture of a final product.

A lot of native vegetable oils or fats have only limited applications in their original form because of their specific chemical composition. To expand their utility, vegetable oils can be modified either chemically by hydrogenation or interesterification or physically by fractionation [2-4]. In general, interesterification has become a useful tool in the fats' and oils' industry for modification of both the structure and properties of fats [2]. Chemical interesterification is an alternative to the undesirable partial hydrogenation process that can be developed to obtain fats and oils with a desired functionality. Moreover, chemical interesterification allows to obtain fats that have low trans-isomer content or are trans-isomer free [5]. As part of interesterification, fatty acids (FA) are not altered, but redistributed within triacylglycerol molecule or between triacylglycerols. Thus, this kind of chemical modification breaks the existing ester bonds and forms new bonds in glycerol molecules. Chemical interesterification leads to a random distribution of fatty acids among all three stereospecific positions [5]. Therefore, chemical interesterification modifies the structure of triacylglycerols (TAG) and such physical properties of fats as crystallization 
behavior and melting point, solid fat content, and texture, contributing to a greater availability of fat fractions for final product applications [6].

An emulsion is a colloidal dispersion of two immiscible liquid phases, with one liquid phase present as small spherical droplets (the dispersed phase) in the other (the continuous phase). From the thermodynamic point of view, emulsions are unstable systems. The usual mechanisms leading to physical instability of emulsions include creaming, sedimentation, flocculation, coalescence, or Ostwald ripening [7]. A great deal of theoretical and experimental research has been carried out to establish the factors that determine rheology and stability of emulsions. The correct amount and type of emulsifier added to the system is one of them. Diacylglycerols (DAG) at different degrees of purity are used as additives or carriers in food, medicine, and cosmetic industries. With a hydrophilic hydroxyl group in the molecular structure, diacylglycerols exhibit interfacial properties and surface activity which make them suitable as emulsifiers [8].

Chicken and turkey are the main ingredients of meat products in Europe, beside pork, and beef [9]. The turkey fat is obtained by food industry mainly from turkey production waste. The average fat content in turkeys is $15 \%$ of their weight [10]. Unfortunately, it is not a valuable consumer product despite its low price [11]. Currently, turkey fat is used as a component of poultry products. It can also be found in products such as sausages, smoked meats, sandwich products, and in ready-made dishes. It is also a component of animal feed [12]. Poultry and fish meat and fat are considered good sources of polyunsaturated fatty acids (PUFA), moreover, occurring at favorable ratios [13]. Poultry fats are more easily absorbed than beef and pork fats. They additionally contain more vitamins (A, E) as well as carotenes [14]. The bioactive component present in turkey fat is conjugated linoleic acid (CLA) [15]. Conjugated linoleic acid has a broad range of effects on the human body, including antioxidant, antineoplastic, or bacteriostatic action $[16,17]$. Moreover, turkey fat contains larger amounts of CLA than, for example, pork [18].

Sesame oil is one of the world's most important oils and has been regarded as a nutritious food. The antioxidant activity of sesame oil and its various healthful properties are attributed to the presence of various bioactive components like phytosterols, tocopherols, and flavonoids as well as lignans sesamin and sesamolin [19]. Moreover, sesame oil is a supplement with known anti-inflammatory properties and can reduce the risk of cardiovascular disease. Current studies have shown that this oil can reduce low-density lipoprotein (LDL) while maintaining high-density lipoprotein (HDL) levels [20]. Sesame oil is extremely resistant to oxidative rancidity [21]. From the consumers' point of view, sesame oils have a mild odor and a pleasant taste [22].
Literature offers no data concerning chemical modification of turkey fat. Therefore, chemical interesterification of this fat with sesame oil was carried out to find an application for food industry waste, i.e., turkey fat, by enriching and improving its composition with unsaturated fatty acids derived from oil.

The purpose of this study was to form new dispersion systems based on chemically interesterified waste turkey fat containing sesame oil (2:3 wt./wt.) and to evaluate effectiveness of synthetized diacylglycerols stabilizing these emulsions. The role of the amount of synthetically obtained diacylglycerols (DAG) as emulsifiers in obtaining the stable emulsion product were examined.

\section{Materials and methods}

\section{Materials}

Monoacylglycerols (MAG) were donated by Oleon NV (Oelegem, Belgium). Their composition was as follows: 95.1\% MAG, 3.8\% DAG, and 0.3\% free glycerol and the acid value was $1.6 \mathrm{mg} \mathrm{KOH} / \mathrm{g}$. The fatty acid composition was as follows: C16:0 (7.9\%), C18:2 (53.5\%), C18:1t (3.1\%), C18:1c (35.2\%), and C18:3 (0.3). The values presented are stated in the manufacturer's certificate. To obtain high-purity diacylglycerols, the following reagents were used: sulfuric acid (VWR Prolabo; > 95\%), petroleum ether (Acros Organics; for analysis), sodium hydrogen carbonate (Merck; for analysis), ethyl acetate (Fisher Scientific; $>99 \%$; laboratory reagent grade), acetic acid (Chem-lab; >99\%; analytical reagent), methanol (VWR Prolabo; technical), and silica gel for chromatography 0.060-0.200 mm 60A (Acros Organics).

Sesame oil (SO) was purchased at a local market (produced by Oleofarm). Turkey male fat (TMF) was obtained from a private ecological farm. The choice of oil was dictated by the results of a survey which indicated that consumers are not interested in turkey fat because of its specific smell, unsuitable for a majority of respondents. By contrast, sesame oil was described as characterized by a pleasant smell and flavor preferred by consumers. Sodium methoxide (Acros Organics, anhydrous, pure) served as a catalyst during chemical interesterification. Other reagents used during the reaction: phosphoric acid (Acros Organics; $85 \%$ solution in water; extra pure), diethyl ether (Acros Organics; for analysis), and magnesium sulfate (Vel N.V.; dried; extra pure). For GC analysis, 37-Component F.A.M.E. mix, C4-C24 (Supelco), n-hexane (Vel N.V.; for analysis), sodium hydroxide (Fisher Scientific; 98.4\%; analytical reagent), and methanol (Acros Organics, gradient grade) were used. Carboxymethylcellulose obtained from Barentz Hoofddorp, The Netherlands, was employed as a thickener 
for emulsions. Sodium benzoate was applied as a preservative (Orff Food Eastern Europe).

\section{METHODS}

\section{Synthesis of DAG}

Diacylglycerols were obtained through intermolecular combination of acyl moieties from different MAG into one molecule, producing an equimolar amount of glycerol. For this purpose, equal amounts ( $150 \mathrm{~g})$ of MAG and petroleum ether were mixed and heated to the reflux temperature of petroleum ether. When the temperature was reached, $0.088 \mathrm{~mol} / \mathrm{mol}$ of catalyst (95\% sulfuric acid) was added. After $60 \mathrm{~min}$, the catalyst was neutralized by adding the appropriate amount (equimolar to the sulfuric acid) of $\mathrm{NaHCO}_{3}$ aqueous heated solution and the reaction was interrupted. The mixture was cooled and phases were separated. Petroleum ether from the top layer was evaporated.

\section{Purification of DAG}

To obtain high-purity DAG, column chromatography was applied. Silica gel was packed into the column $(500 \times 50 \mathrm{~mm}$ glass column). The reaction mixture was dissolved in petroleum ether (1:1 ratio, wt./wt.) and then in approximately $500 \mathrm{~g}$ of silica gel. The mixture was placed into an oven at $70{ }^{\circ} \mathrm{C}$ until only dry powder remained. The powder was transferred to the top of the prepared column. The column was eluted with different solvent mixtures (Table 1). Samples $(20 \mathrm{~mL})$ were collected and analyzed by TLC.

\section{Analysis of DAG}

Every second (1, 3, 5, 7, etc.) sample collected from the column was spotted on a TLC (silica gel $60 \mathrm{~W}$ ) plate for a qualitative analysis. A mixture of petroleum ether-ethyl acetate-acetic acid (90:10:1 (v/v)) was used as an elution system. Visualization was carried out by spraying the plate

Table 1 Solvent mixtures applied for column elution

\begin{tabular}{lll}
\hline Volume (mL) & Solvents & Mixture (v/v) \\
\hline 500 & Petroleum ether (I) & 100 \\
1400 & $\begin{array}{l}\text { Petroleum ether/ethyl acetate/acetic } \\
\text { acid (II) }\end{array}$ & $90: 10: 1$ \\
& $\begin{array}{l}\text { Petroleum ether/ethyl acetate/acetic } \\
1300\end{array}$ & $80: 20: 1$ \\
& $\quad$ acid (III) \\
400 & Petroleum ether/ethyl acetate/acetic & $70: 30: 1$ \\
& $\quad$ acid (IV) & \\
100 & Petroleum ether/ethyl acetate (V) & $50: 50$ \\
100 & Ethyl acetate (VI) & 100 \\
350 & Methanol (VII) & 100 \\
\hline
\end{tabular}

with $95 \% \mathrm{H}_{2} \mathrm{SO}_{4}$ and heating for $10 \mathrm{~min}$ at $120{ }^{\circ} \mathrm{C}$. Samples containing the same components were combined.

Selected samples were analyzed by means of gel permeation chromatography (GPC) using an Agilent 1100 series system (Diegem, Belgium) equipped with a refractive index detector. Tetrahydrofuran stabilized with $0.025 \%$ BHT was used as the mobile phase. Isocratic elution was applied to a Phenogel (Phenomenex, Utrecht, The Netherlands) $5 \mu \mathrm{m}$, $500 \AA$ LC, $300 \times 7.8 \mathrm{~mm}$ column at room temperature.

The selection of DAG synthesis, purification, and analysis procedures was based on a previous publication [23].

\section{Chemical interesterification}

Turkey male fat and sesame oil at the ratio 2:3 (wt./wt.) were placed into a single-necked round-bottom flask (magnetic stirring was applied). The interesterification was performed in the closed flask at $90{ }^{\circ} \mathrm{C}$ (in an oil bath) for $2 \mathrm{~h}$. After $15 \mathrm{~min}$ of heating, when the appropriate temperature was reached, the catalyst sodium methoxide $(0.6 \%$ of mixture mass) was added and the time of reaction was measured starting from this moment. After a predetermined time, the catalyst was neutralized by adding $50 \mathrm{~cm}^{3}$ of diluted $\mathrm{H}_{3} \mathrm{PO}_{4}$-heated solution and the reaction was discontinued. Afterwards, the mixture was cooled and extraction with diethyl ether $(3 \times 80 \mathrm{~mL})$ was performed. The aqueous phase was removed together with products of the reaction between the catalyst and phosphoric acid. The organic phase was dried by adding anhydrous magnesium sulfate $(5 \mathrm{~g})$, then, the mixture was filtered, and the solvent was evaporated. $0.6 \%$ of catalyst was used in the interesterification reaction, but the total amount was greater, because fats contained water $(0.1 \%)$ and a small amount of free fatty acids (FFA), which destroyed the catalyst. Therefore, it was necessary to measure the water amount in the substrates by means of Karl Fischer titration and determine the amount of FFA by means of potentiometric titration.

\section{Fatty acid composition}

The composition of fatty acids (FA) of sesame oil and animal fat was determined using gas chromatography (GCFID) after conversion of the fats to fatty acid methyl esters (FAMEs). Identification and quantification of the fatty acids was performed by comparison (as per internal standard) of the retention times with those of a standard mixture of FAMEs and then calculation of the response factors for each fatty acid. The analysis was carried out using the Agilent Technologies 6890N Network GC System with a capillary column (ZebronTM (ZB-5MS), $L=30 \mathrm{~m} \times$ I.D. $=$ $0.25 \mathrm{~mm} \times d f=0.25 \mu \mathrm{m})$. Front inlet: splitless injection at $250{ }^{\circ} \mathrm{C}$ and front detector: flame ionization detector (FID) $300{ }^{\circ} \mathrm{C}$. Heating method: $50{ }^{\circ} \mathrm{C}\left(2^{\prime}\right)--\left(10^{\circ} \mathrm{C} / \mathrm{min}\right)--220^{\circ} \mathrm{C}$ 
(5 min)--(10 $\left.{ }^{\circ} \mathrm{C} / \mathrm{min}\right)--300{ }^{\circ} \mathrm{C}$. The flow rate of carrier gas (helium) was $1.5 \mathrm{~mL} \mathrm{~min}^{-1}$. The values were presented as a mean of three measurements.

\section{Content of polar fraction}

The content of polar fraction in fat blends before and after interesterification was determined using gel permeation chromatography (GPC) by Agilent 1100 series with a refractive index detector. Isocratic elution was performed with tetrahydrofuran (THF). The separation was achieved by a Phenogel column (Phenomenex, $300 \times 7.80 \mathrm{~mm}, 5 \mu \mathrm{m}$, $100 \AA$ ). The samples solvent was also THF.

\section{Crystallization point determination}

Rheological measurements were performed to determine the crystallization point of the examined fats. Oscillatory tests using a RheoStress 1 Rotational Rheometer (Thermo) equipped with a parallel plate measuring geometry with a $0.5 \mathrm{~mm}$ gap and refrigerated cooling system were performed. The test parameters were as follows: A-factor: $23,580 \mathrm{~Pa} /$ $\mathrm{Nm}$, M-factor: $59.95(1 / \mathrm{s}) /(\mathrm{rad} / \mathrm{s})$, moment of inertia: $1.56 \times 10^{-5} \mathrm{~kg} \mathrm{~m}^{2}$, damping: 30 , expansion coefficient: $1100 \mu \mathrm{m} /{ }^{\circ} \mathrm{C}$, and torque offset: off. The preheated sample was placed on a preheated plate $\left(60^{\circ} \mathrm{C}\right)$, and the viscosity was measured as a function of temperature (from $60{ }^{\circ} \mathrm{C}$ to $-10^{\circ} \mathrm{C}$ ). The crystallization point was read from the curve refraction.

\section{Preparation of emulsions}

Emulsions were prepared according to recipes based on our own experience. The influence of the amount of emulsifiers (DAG) was determined by adding an increasing amount of this compound to the oil phase of the emulsion (Table 2). Carboxymethylcellulose was dispersed in distilled water. Both phases (oil and aqueous) were heated at $50-55{ }^{\circ} \mathrm{C}$ in a water bath. The phases were homogenised using a high shear mixer at a uniform speed of $18500 \mathrm{rpm}$ for $4 \mathrm{~min}$. Finally, the emulsions were cooled to room temperature and a preservative (sodium benzoate) was added. The total mass of each emulsion was $100.0 \mathrm{~g}$.

\section{Determination of average particle size and particle size distribution}

The average droplet size and distribution were determined after $24 \mathrm{~h}, 4$, and 16 weeks. The samples were stored at room temperature $\left(22-23{ }^{\circ} \mathrm{C}\right)$. For the purpose of measurements, the emulsions were diluted 1:200 with distilled water. Droplet size was measured in the range $0.12-704 \mu \mathrm{m}$ by laser diffraction using a Microtrac Particle Size Analyzer (Leeds
Table 2 Composition and parameters of emulsions

\begin{tabular}{llllll}
\hline Component [\%wt/wt] & \multicolumn{3}{l}{ Emulsion } & & \\
\cline { 2 - 6 } & I & II & III & IV & V \\
\hline Water & 66.7 & 64.7 & 62.7 & 60.7 & 58.7 \\
DAG $^{\mathrm{a}}$ & 2.0 & 4.0 & 6.0 & 8.0 & 10.0 \\
Interesterified turkey fat with & & & 30.0 & & \\
$\quad$ sesame oil at the ratio (2:3 wt./ & & & & & \\
$\quad$ wt.) & & & & & \\
Carboxymethylcellulose & & & 0.3 & & \\
Sodium benzoate & & & 0.3 & & \\
\hline
\end{tabular}

${ }^{\text {a }}$ The total amount of DAG in emulsions was greater, because interesterified fats contained DAG. However, the addition of DAG was the same for each emulsion

\& Northrup, Philadelphia, USA); the total time of each measurement was $30 \mathrm{~s}$. The measurements were repeated three times and given as the mean value. Average particle (droplet) size (D) was presented as a mean diameter $[\mu \mathrm{m}]$ of the volume distribution and was calculated according to the following formula:

$D=\frac{\sum_{i} V_{i} d_{i}}{\sum_{i} V_{i}}$

where $V$ volume percentage in a channel size and $d$ channel diameter in microns. Mean particle size was presented of the volume distribution, which represents the center of gravity of the distribution.

\section{Dispersion index}

It was calculated on the basis of particle size measurements using dynamic laser diffraction according to the formula:

$k=(A-B) / C$,

where $A, B$, and $C$ are the biggest sizes of oil droplets for 90,10 , and $50 \%$ of all particles, respectively.

\section{Turbiscan measurements}

Destabilization of the emulsions was evaluated using the Turbiscan test (Turbiscan Lab. Formulation, France). Glass cells filled with emulsions were scanned, each $40 \mathrm{~mm}$, with a pulsed near infrared light source $(\lambda=880 \mathrm{~nm})$ and two synchronized detectors. The transmission detector receives the light through a sample at $0^{\circ}$ from the incident beam, while the backscattering detector receives the light scattered by a sample at $135^{\circ}$ from the incident beam. The measurements were performed immediately after preparation of the emulsions and at different times for 2 months, in the same glass cell. The examined samples were stored at room temperature 
for 2 months. The results were presented as the dependency of backscattered light intensity on sample height. By repeating the scan of a sample at different time intervals, stability of the emulsions can be studied in detail. The different line colors represent subsequent measurements. Analysis of curves illustrating percentage of backscattered light for the studied emulsions over time allowed for evaluation of intensity of destabilization occurring in the samples. The Turbiscan test software allows to overlay the backscattered light intensity profiles one on another on a single graph to show the variations. It is generally said that a stable emulsion shows profiles that are constant and not different from the first curve, whereas an unstable product shows the profiles to vary.

\section{Results and discussion}

\section{Characteristic of the dag}

\section{DAG synthesis and purification}

GPC chromatograms confirmed a pure fraction of DAG was obtained after column chromatography. Figure 1 presents the differences between DAG after synthesis (a) and after purification (b). Thus, column chromatography can be considered as a suitable technique for DAG purification. The biggest disadvantage of this method is the high consumption of eluents, which affects environmental and economic parameters. However, it was found that mixing the product with silica gel before the purification was very favorable and resulted in reduction of the total amount of silica gel used. Hence, the economic and environmental value of the method was increased and the existing method [23] was optimized.

\section{Characteristics of the fats}

\section{Fatty acid profiles of fats}

The fatty acid profiles of raw fats, initial blend, and blend after interesterification are presented in Table 3. Analysis of sesame oil composition showed linoleic acid, which accounted for $54.8 \%$, to be the major fatty acid. Saturated fatty acids constitute about $15 \%$. Palmitic acid (31.7\%), oleic acid $(27.6 \%)$, and linoleic acid (18.3\%) were the main components of turkey male fat, while its saturated fatty acids (SFA) constitute about $40 \%$ (Table 3 ). Turkey fat contained a lower amount of saturated fatty acids than lard or mutton tallow [24, 25]. However, according to [26], it contained more SFA than chicken fat.

The total fatty acid profile of the blend before and after chemical interesterification remained practically unchanged
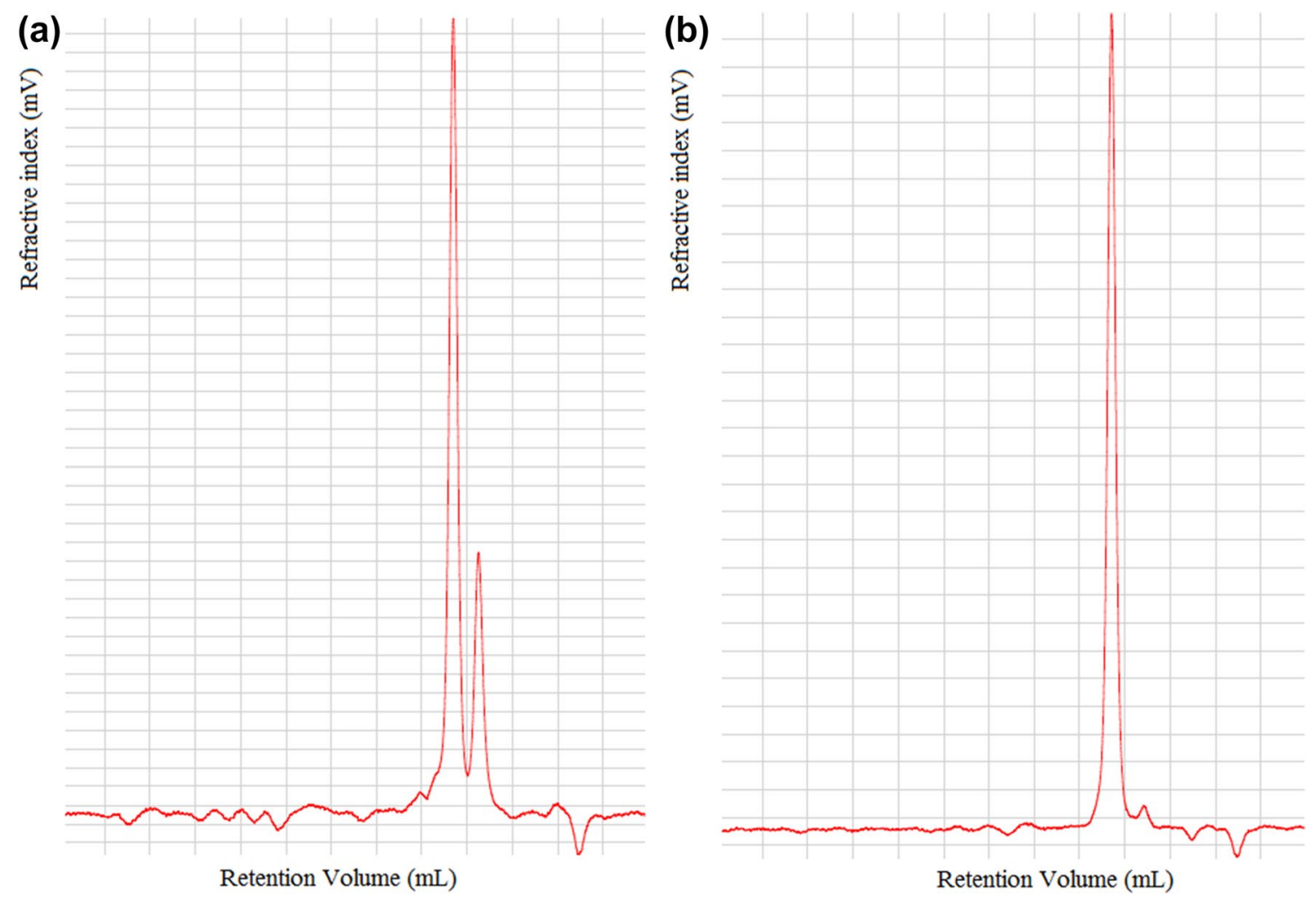

Fig. 1 GPC chromatograms of synthesized DAG $\mathbf{a}$ before purification and $\mathbf{b}$ after column chromatography 
Table 3 Fatty acid composition of the examined fats (mean of three $(n=3)$ measurements \pm standard deviation)

\begin{tabular}{llllllllll}
\hline Fat sample & \multicolumn{1}{l}{ Fatty acid compositions (\%) } \\
\cline { 2 - 9 } & C-14:0 & C-15:0 & C-16:1 & C-16:0 & C-17:0 & C-18:2 & C-18:1 & C-18:0 & C-18:3 \\
\hline Sesame oil SO & nd & nd & nd & $12.0 \pm 0.2$ & nd & $54.8 \pm 1.0$ & $27.1 \pm 0.7$ & $2.6 \pm 0.2$ & $3.5 \pm 0.2$ \\
Turkey male fat TMF & $0.7 \pm 0.1$ & $0.3 \pm 0.0$ & $11.1 \pm 0.4$ & $31.7 \pm 0.5$ & nd & $18.3 \pm 0.6$ & $27.6 \pm 1.2$ & $7.4 \pm 0.5$ & $3.0 \pm 0.1$ \\
Physical mixture 60\% SO+40\% TMF & $0.4 \pm 0.2$ & nd & $5.6 \pm 0.6$ & $21.1 \pm 0.1$ & nd & $39.3 \pm 0.7$ & $25.3 \pm 0.5$ & $5.1 \pm 0.2$ & $3.2 \pm 0.2$ \\
Chemical mixture 60\% SO+40\% TMF & nd & nd & $4.9 \pm 0.3$ & $21.1 \pm 0.3$ & nd & $36.9 \pm 1.1$ & $26.8 \pm 0.4$ & $7.1 \pm 0.4$ & $3.3 \pm 0.4$ \\
\hline
\end{tabular}

$n d$ not detected

(Table 3), which is in agreement with numerous studies concerning chemical interesterification [27-29]. Therefore, interesterification reaction has no influence on the fatty acid composition of a fat blend. As a consequence, this modification can be qualified as an alternative technology for partial hydrogenation, which can lead to formation of deleterious trans-isomers.

\section{Crystallization point of fats}

The crystallization point of sesame oil was not determined; the literature [30] reports it is within the range -3 to $-4{ }^{\circ} \mathrm{C}$. This low value can be explained by the high content of unsaturated fatty acids, due to which the onset of crystallization occurred at a low temperature. It was noted that pure turkey male fat showed a crystallization point of $-3{ }^{\circ} \mathrm{C}$. The addition of sesame oil decreased the value to $-7{ }^{\circ} \mathrm{C}$ and after chemical interesterification increased it to $-5{ }^{\circ} \mathrm{C}$ (Fig. 2a).

\section{Content of polar fraction}

The results obtained confirmed that new acylglycerols appeared after the interesterification reaction. The fatty blend before interesterification contained TAG and a low amount of FFA, while after the reaction, a higher amount of FFA was noted and appearance of DAG was additionally observed. The amount of MAG was not significant. A higher amount of FFA in the interesterified blend was also confirmed by determining acid value. An increase of FFA content, by $5 \%$ in relation with the initial blend, was observed in the interesterified blend (Fig. 2b). The above data confirmed an alteration of the acylglycerols structure and exchange of fatty acids within and between TAG molecules, which in turn allows to claim that new TAG were formed. According to [31, 32], these observations lead to emergence of new interactions between TAG. Within the context of this study, the presence of DAG is very favorable, because they are seen as good emulsifiers [25].

\section{Characteristics of the emulsions}

\section{Particle size and distribution of the emulsions}

Results of laser diffraction measurements performed $24 \mathrm{~h}$ after manufacturing demonstrated $4 \mu \mathrm{m}$ was the average particle size of emulsions I, III, IV, and V. Only emulsion II exhibited a much greater particle diameter $-13.3 \mu \mathrm{m}$ (Fig. 3a). Statistical analysis showed a low correlation between DAG content and average particle size of the examined emulsions $(c=-0.30)$. In general, an increase of average particle size was observed after successive measurements. The highest increase was observed after 4 weeks of storage. Emulsions I and II were characterized by the highest average particle sizes after this time (44.8 and $38.9 \mu \mathrm{m}$, respectively). There was a possibility of laser diffraction determination after 16 weeks only for samples which contained more emulsifier (emulsions III, IV, and V) due to the advanced stage of destabilization processes in the remaining systems. Values of particle sizes for emulsions III-V were in the range 51.1-54.8 $\mu \mathrm{m}$.

Particle size distribution of the emulsions determined $24 \mathrm{~h}$ after manufacturing showed only one fraction for emulsions I, II, IV, and V (Fig. 4). Emulsions I and II (a)

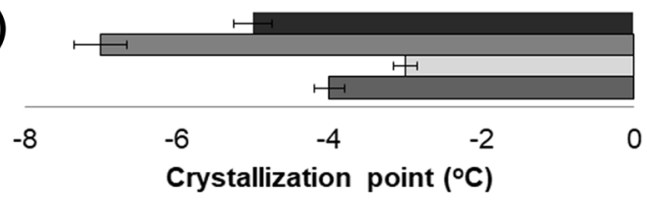

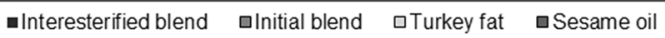

(b)

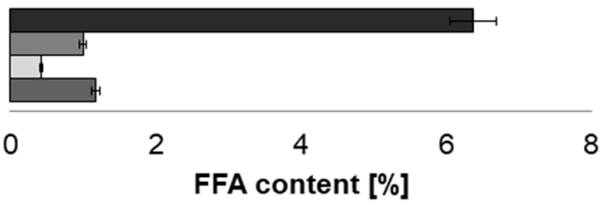

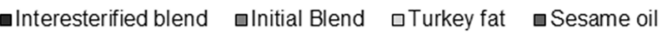

Fig. 2 Characteristics of fats $\mathbf{a}$ crystallization points and $\mathbf{b}$ free fatty acid content 

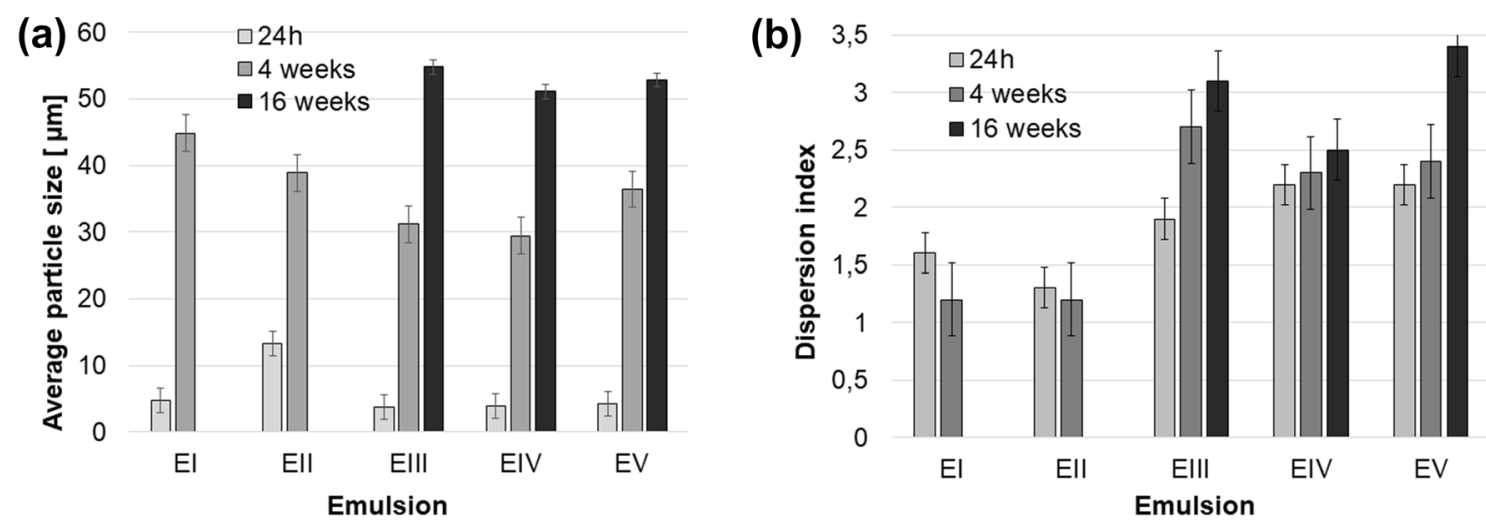

Fig. 3 Laser diffraction results: a average particle size and $\mathbf{b}$ dispersion index 24 h, 4, and 16 weeks after manufacturing
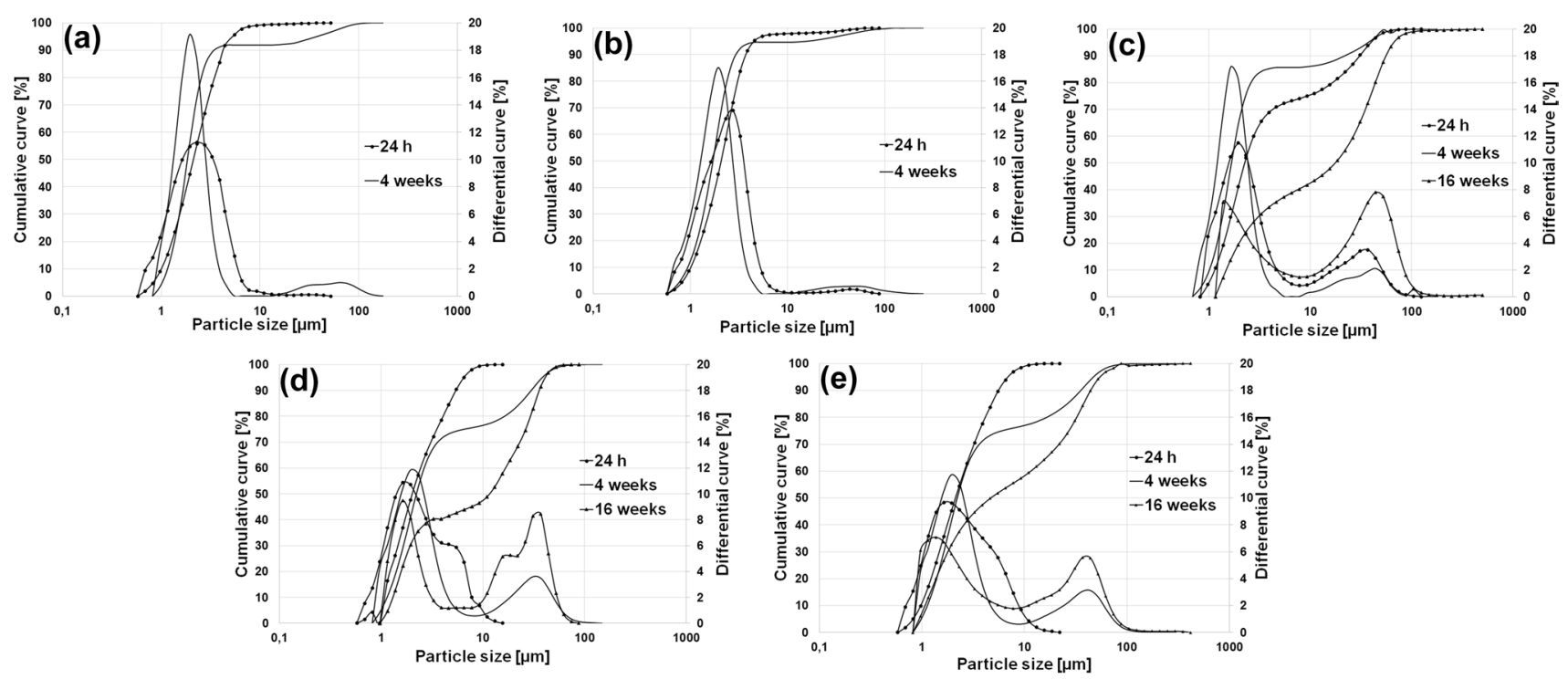

Fig. 4 Particle size distribution of the examined emulsions: a emulsion I, $\mathbf{b}$ emulsion II, $\mathbf{c}$ emulsion III, $\mathbf{d}$ emulsion IV, and $\mathbf{e}$ emulsion V

exhibited one fraction also after 4 weeks of storage. Size variations of droplets were observed for emulsions I and II. Moreover, for both emulsions, a new peak occurred at the end of the curve, which suggests the beginning of a phase separation process. This was confirmed for these emulsions (I and II) by observation of a considerable increase of average particle size after 4 weeks of storage. Emergence of a second fraction was observed in the case of emulsions IV and V, causing a wider droplet distribution (Fig. 4). Furthermore, higher values of the dispersion index for these systems were reported after this time (Fig. 3b). According to [33], a high dispersion index value is evidence of variation of droplet diameters, whereby an early phase separation process becomes more likely. The last measurement (after 16 weeks) showed a further increase of average particle size of emulsions III, IV, and
V (Fig. 3a), which resulted in translocation of the curve (particle rearrangement) (Fig. 4).

\section{Turbiscan test of the emulsions}

Intensity of the light backscattered by a sample depends on the following parameters: average diameter of particles, their volume fraction, and relative refractive index between the dispersed and continuous phases. Any change due to a variation of the particle size (flocculation and coalescence) or a local variation of the volume fraction (migration phenomena: creaming and sedimentation) can be detected optically [34].

According to $[35,36]$, creaming occurs when the dispersed phase has lower density than the continuous phase. This phenomenon could appear together with coalescence 
or flocculation and lead to phase separation. Creaming can be easily detected by means of the Turbiscan test, because it induces changes in concentration of particles in the top and the bottom of a measuring cell.

In general, the Turbiscan test makes scans at various preprogrammed periods and overlays their profiles on one graph to show the destabilization. Graphs are usually displayed in reference mode, whereby the first profile is subtracted from all other profiles, to enhance visualization of variations. The backscattered light intensity as a function of sample height of emulsion I is presented in Fig. 5a. A decrease of backscattered (BS) light intensity was observed at the bottom of the cell due to a fall of droplet concentration in this area, whereas at the top of the cell, an increase of BS light was observed because of droplet movements (creaming). These results suggested that the amount of emulsifier was not sufficient to properly stabilize the system.

Knowing that these destabilization phenomena occur, the formulation can be modified accordingly and a stable product can be obtained. Typically, in this case, the addition of an emulsifier should improve stability as well as reduce migration and contact of oil droplets, which lead to coalescence and other migration phenomena.

In general, dispersions rarely undergo only one kind of instability, usually several instabilities occur at the same time. The Turbiscan test allows for a macroscopic visualization of concentrated dispersion stability, and hence separation and detection of different instabilities [37]. Like in emulsion I, creaming was observed in emulsion II as well (BS light intensity decreased at the bottom of the measuring cell). This process started relatively early (Fig. 5b). During the first few days, changes were observed (curves did not overlap) in the intensity of BS light. Moreover, variations of the backscattering profiles indicated changes of emulsion particle size. This led to the assumption that different types of instability, characteristic for coalescence or flocculation, occurred in parallel with creaming.

There is no evidence of changes of the BS light intensity curves of emulsions III, IV, and V-the curves overlapped (the representative Fig. 5c). This kind of record is proof of the systems' proper condition and absence of changes in the profile indicates excellent stability of the emulsions during the whole storage period.

Changes in appearance of the examined emulsions (I-V) were also observed. A visible inequality of emulsions I and II was noted at the bottom of the measuring cell, thereby confirming instability of these systems. In the case of the three remaining systems, destabilization changes were not observed, the image was uniform and the color was consistent.
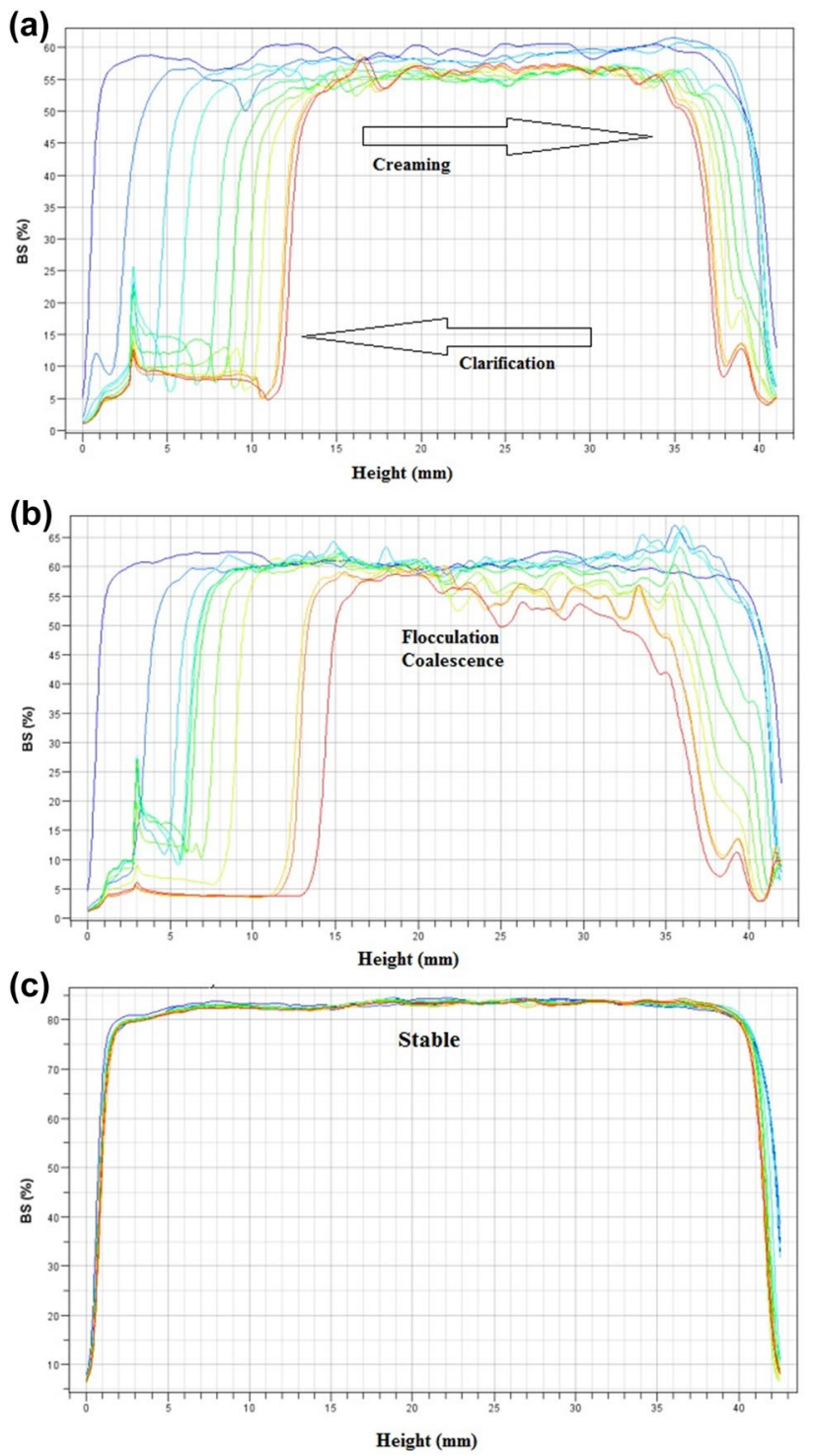

Fig. 5 Backscattered light (BS) intensity as a function of sample height for emulsion a I, b II, c representative for III, IV, and V, during 2 months of storage. The different colors of lines represent the subsequent measurements

\section{Conclusion}

Pure DAG were obtained using an existing synthesis method and complementing it with a new purification approach, using column chromatography, increasing in this way the economic and environmental value of the existing method.

The chemically obtained interesterified fat blend of turkey fat and sesame oil contained practically the same fatty acids as the initial blend (before interesterification). The content of free fatty acids as well as diacylglycerols increased in the fat blend after the chemical modification. The crystallization point also changed-increasing by $2{ }^{\circ} \mathrm{C}$. 
Some emulsions were successfully derived from the new products proposed in this study (interesterified turkey fat and synthetic diacylglycerols). Nevertheless, the proposed amounts of DAG for emulsions I and II were not sufficient for proper stabilization. In the case of other emulsions, suitable stability was confirmed. $6 \%$ (wt./wt.) was found to be the smallest amount of DAG needed to obtain a stable emulsion product. However, in our opinion, further research should focus on obtaining a lower droplet size as the average particle sizes of approximately $50 \mu \mathrm{m}$ were found after the storage period. Research is planned to continue to produce a smaller emulsion particle (smaller dispersion) and to propose a different composition of structured diacylglycerols or introduce changes such as time or rotation speed during homogenization.

Acknowledgements The authors wish to thank the University of Technology and Humanities in Radom, University of Antwerp and Warsaw Agricultural University for financial support.

Conflict of interest All the authors declare that they have no conflict of interest.

Open Access This article is distributed under the terms of the Creative Commons Attribution 4.0 International License (http://creativeco mmons.org/licenses/by/4.0/), which permits unrestricted use, distribution, and reproduction in any medium, provided you give appropriate credit to the original author(s) and the source, provide a link to the Creative Commons license, and indicate if changes were made.

\section{References}

1. Hill K (2000) Fats and oils as oleochemical raw materials. Pure Appl Chem 72:1255-1264

2. Kowalska D, Gruczyńska E, Kowalska M (2015) The effect of enzymatic interesterification on the physico-chemical properties and thermo-oxidative stabilities of beef tallow stearin and rapeseed oil blends. J Therm Anal Calorim 120:507-517

3. Kowalska M, Mendrycka M, Żbikowska A, Stawarz S (2015) Enzymatically interesterified fats based on mutton tallow and walnut oil suitable for cosmetic emulsion. Int J Cosmet Sci 37:82-91

4. Danthine S, Lefe'bure E, Nhu Trinh H, Blecker C (2014) Effect of palm oil enzymatic interesterification on physicochemical and structural properties of mixed fat blends. J Am Oil Chem Soc 91:1477-1487

5. Ribeiro APB, Grimaldi R, Gioielli LA, Gonçalves LA (2009) Zero trans fats from soybean oil and fully hydrogenated soybean oil: physico-chemical properties and food applications. Food Res Int 42:401-410

6. Dian NLHM., Sundram K, Idris NA (2007) Effect of chemical interesterification on triacylglycerol and solid fat contents of palm stearin, sunflower oil and palm kernel olein blends. Eur J Lipid Sci Tech 109:147-156

7. Kundu P, Agrawal A, Mateen H, Mishra IM (2013) Stability of oil-in-water macro-emulsion with anionic surfactant: Effect of electrolytes and temperature. Chem Eng Sci 102:176-185
8. Miklos R, Zhang H, Lametsch R, Xu X (2013) Physicochemical properties of lard-based diacylglycerols in blends with lard. Food Chem 138:608-614

9. Köppel R, Ruf J, Zimmerli F, Breitenmoser A (2008) Multiplex real-time PCR for the detection and quantification of DNA from beef, pork, chicken and turkey. Eur Food Res Technol 227:1199-1203

10. Chizzolini R, Zanardi E, Dorigoni V, Ghidini S (1999) Calorific value and cholesterol content of normal and low-fat meat and meat products. Trends Food Sci Technol 10:119-128

11. Laudadio V, Tufarelli V, Dario M, D'emilio FP, Vicenti A (2009) Growth performance and carcass characteristics of female turkeys affected by feeding programs. Poult Sci 88:805-810

12. Renerre M, Poncet K, Mercier Y, Gatellier P, Metro B (1999) Influence of dietary fat and vitamin $\mathrm{E}$ on antioxidant status of muscles of turkey. J Agric Food Chem 47:237-244

13. Komprda T, Zelenka J, Fajmonova E, Fialova M, Kladroba D (2005) Arachidonic acid and long-chain $n-3$ polyunsaturated fatty acid contents in meat of selected poultry and fish species in relation to dietary fat sources. J Agric Food Chem 53:6804-6812

14. Aumaître A (1999) Quality and safety of animal products. Livest Sci 59:113-124

15. Chin SF, Storkson JM, Albright KJ, Cook ME, Pariza MW (1994) Conjugated linoleic acid is a growth factor for rats as shown by enhanced weight gain and improved feed efficiency. J Nutr 124:2344

16. Koba K, Yanagita T (2014) Health benefits of conjugated linoleic acid (CLA). Obes Res Clin Pract 8:525-532

17. Banjamin S, Spener F (2009) Conjugated linoleic acid as functional food: an insight into their health benefits. Nutr Metab 6:36-48

18. Fritsche J, Steinhart H (1998) Amounts of conjugated linoleic acid (CLA) in German foods and evaluation of daily intake. Eur Food Res Technol 206:77-82

19. Latif S, Anwar F (2011) Aqueous enzymatic sesame oil and protein extraction. Food Chem 125:679-684

20. Hsu E, Parthasarathy S (2017) Anti-inflammatory and antioxidant effects of sesame oil on atherosclerosis: a descriptive literature review. Cureus 9:e1438

21. Dimitrios B (2006) Sources of natural phenolic antioxidants. Trends Food Sci Technol 17:505-512

22. Hai Z, Wang J (2006) Electronic nose and data analysis for detection of maize oil adulteration in sesame oil. Sens Actuators B Chem 119:449-455

23. Pazdur Ł, Geuens J, Sels H, Tavernier SM (2015) Low-temperature chemical synthesis of high-purity diacylglycerols (DAG) from monoacylglycerols (MAG). Lipids 50:219-226

24. Bryś J, Wirkowska M, Górska A, Ostrowska-Ligęza E (2012) The use of Lipozyme RM IM for modifying the properties of lard. Cheminè technologija 3:19-21

25. Kowalska M, Żbikowska A, Kowalski B (2014) Enzymatically modified fats based on mutton tallow and rapeseed oil suitable for fatty emulsions. J Am Oil Chem Soc 91:1703-1710

26. De Marchi M, Riovanto R, Penasa M, Cassandro M (2012) Atline prediction of fatty acid profile in chicken breast using near infrared reflectance spectroscopy. Meat Sci 90:653-657

27. Wirkowska M, Bryś J, Kowalski B (2005) Stabilność przeciwutleniająca przeestryfikowanych mieszanin tłuszczu mlekowego z olejem rzepakowym. Zywn-Nauk Technol Ja 12:265274 (in Polish)

28. Berry SE (2009) Triacylglycerol structure and interesterification of palmitic and stearic acid-rich fats: an overview and implications for cardiovascular disease. Nutr Res Rev 22:3-17

29. Bryś J, Gruczyńska E, Kowalski B, Tarnowska K (2004) Przeestryfikowanie mieszanin tłuszczu mlecznego i oleju rzepakowego. Zywn-Nauk Technol Ja 3:18-26 (in Polish) 
30. Gunstone F (ed) (2011) Vegetable oils in food technology: composition, properties and uses. Blackwell, Oxford

31. Silva RC, Cotting LN, Poltronieri TP, Balcão VM, Gioielli LA (2009) Physical properties of structured lipids from lard and soybean oil produced by enzymatic interesterification. Food Sci Technol (Campinas) 29:652-660

32. Kowalski B, Tarnowska K, Gruczynska E (2005) The properties of the mixture of beef tallow and rapeseed oil with a high content of tallow after chemical and enzymatic interesterification. Grasas Aceites 56:267-275

33. McClements DJ (2007) Critical review of techniques and methodologies for characterization of emulsion stability. Crit Rev Food Sci Nutr 47:611-649
34. Huck-Iriart C, Candal RJ, Herrera ML (2011) Effect of processing conditions and composition on sodium caseinate emulsions stability. Proc Food Sci 1:116-122

35. Gupta A, Eral HB, Hatton TA, Doyle PS (2016) Nanoemulsions: formation, properties and applications. Soft matter 12:2826-2841

36. Robins MM (2000) Emulsions_-creaming phenomena. Curr Opin Colloid In 5:265-272

37. Celia C, Trapasso E, Cosco D, Paolino D, Fresta M (2009) Turbiscan Lab® Expert analysis of the stability of ethosomes ${ }^{\circledR}$ and ultradeformable liposomes containing a bilayer fluidizing agent. Colloids Surf B Biointerfaces 72:155-160 